\title{
Fire Resistance Design of Unprotected Concrete Filled Steel Hollow Sections: Meta-Analysis of Available Furnace Test Data
}

\author{
DAVID RUSH ${ }^{1}$, LUKE BISBY ${ }^{1}$, ATHANASIOS MELANDINOS ${ }^{2}$, and BARBARA LANE ${ }^{2}$ \\ ${ }^{1}$ BRE Centre for Fire Safety Engineering \\ University of Edinburgh, UK \\ ${ }^{2}$ Arup Fire \\ London, UK
}

\begin{abstract}
Concrete filled steel hollow structural sections are an efficient, sustainable, and attractive option for both ambient temperature and fire resistance design of columns in multi-storey buildings and are increasingly common in modern construction practice around the world. Whilst the design of these sections at ambient temperatures is reasonably well understood, and models to predict the strength and failure modes of these elements correlate well with observations from tests, this appears not to be true in the case of fire resistant design. This paper assesses the statistical confidence in available fire resistance design models/approaches that are used in North America and Europe by performing a meta-analysis which compares the available experimental data from large-scale standard fire tests performed around the world against fire resistance predictions from design codes. It is shown that available design approaches carry a large uncertainty of prediction, suggesting that they fail to properly account for fundamental aspects of the underlying mechanics during fire. Current North American design approaches for CFS columns are shown to be considerably less conservative, on average, than those used in Europe.
\end{abstract}

KEYWORDS: concrete, steel, fire resistance, fire testing, structural design, furnace.

\section{INTRODUCTION}

Concrete filled steel hollow structural sections (CFS) are an attractive, efficient, and sustainable means by which to design and construct compressive members in multi-storey buildings. CFS columns consist of hollow steel sections that are in-filled with plain or reinforced concrete to provide, through composite action, superior load carrying capacity and structural fire resistance as compared with unfilled steel tubes. The concrete infill and the steel tube work together to give several benefits both at ambient temperature and during fire. The steel tube acts as stay-in-place formwork during casting of the concrete, thus reducing forming and stripping costs, it can also provide lateral confinement to the infill concrete which enhances the concrete's compressive strength and axial deformability, and it provides a smooth, rugged, architectural surface finish. The concrete infill enhances the fire performance of the column by providing a heat sink and by allowing the steel tube to shed axial load to the concrete core when heated during a fire. This means that unprotected CFS columns can, in many cases, achieve adequate fire resistance without any applied fire protection to the steel tube. The infill concrete also enhances the steel tube's resistance to local buckling, both at ambient temperature and during fire [1].

Various types of concrete filling may be used in practice, including plain (unreinforced) concrete (PC), steel bar reinforced concrete (RC), and, relatively rarely, steel fibre reinforced concrete (FIB). A current trend in ambient temperature design of CFS columns is for the infill concrete to have a high-compressive strength of more than $60 \mathrm{MPa}$ (up to $100 \mathrm{MPa}$ in some cases). CFS sections are now widely specified by architects and engineers and are increasingly being applied in the design and construction of multi-storey and high rise buildings, as members within highly optimized structural frames for which structural fire resistance ratings of two hours or more may be required [2].

Structural fire design guidance is available [1,3-8] for many types of CFS columns. However, much of the available fire resistance design guidance was developed for conventional applications based predominantly on outdated large-scale standard fire tests of short, concentrically loaded, small-diameter columns envisioned for use in braced frames using normal strength concrete (compressive strength of $40 \mathrm{MPa}$ or less). Current fire resistance design models are therefore rather limited in scope, and this makes the design of CFS columns using performance-based approaches very difficult to defend to approving authorities.

This paper presents a review of available code-based fire resistance design approaches for CFS columns in North America [1] and Europe [4]. The goal is to highlight the limits of the available design approaches 
and to evaluate the statistical confidence in the predictive ability of the respective fire resistance design approaches used in these jurisdictions. This is done by comparing code-predicted fire resistance times against observed fire resistance times from standard fire resistance tests carried out worldwide over the past 60 years. The models' ability to predict observed behaviour is assessed and areas where more information or understanding are needed are given. The authors have previously presented a detailed qualitative review of available test data [9], and have identified several areas of concern; fire scenario, materials of construction, sectional properties and response, and mechanical loading of the column during fire are all of interest in the current paper.

Fire tests on CFS columns performed to date have generally used a fire exposure similar to ASTM-E119 [10] or ISO-834 [11]. Neither of these fire scenarios represents well a real fire in a modern, open plan, multi-storey building [12,13], let alone a parametric (natural) design fire [14] such as are increasingly being used in modern fire engineered building designs. The materials of construction specified in modern designs are different in a host of ways from those that have been considered in older tests, mostly with respect to the properties of the infill concrete. For instance, polypropylene and steel fibre blends are being added to infill concretes with strengths in excess of $60 \mathrm{MPa}$ to prevent spalling and to allow removal of internal steel reinforcing cages; this is becoming common yet it has not been rigorously investigated. Response phenomena occur during heating of a CFS column that influence failure but cannot currently be predicted with confidence [15]. The appropriate effective length of CFS columns in fire has received considerable research attention [16], yet available guidance, based almost entirely on computational modelling, may be unconservative. The reasons for and likely location of the formation of local buckling and failure of a CFS column remain unclear [16]. The analysis in this paper seeks to determine whether some of the above uncertainties play roles in the performance of available structural fire design approaches.

\section{FIRE RESISTANCE DESIGN CODES FOR CFS COLUMNS}

This paper focuses only on design approaches currently suggested in North America [1] and in Europe [4]. While other approaches are available (e.g. Refs. [17-19]), these are not considered here.

\section{North American Approach}

North American procedures for the design of CFS columns for fire are all based on work performed by Kodur and colleagues at the National Research Council of Canada (NRCC) [1]. Kodur's 2007 [1] state-ofart review notes that the National Building Code of Canada [20], ASCE-29 [21], ACI 216 [22] and AISC Fire Guide [23] all incorporate the semi-empirically derived design equation developed at NRCC to predict the fire resistance of CFS columns:

$$
R=f \cdot\left(\frac{\left(f^{\prime}{ }_{c}+20\right)}{(K L-1000)}\right) \cdot D^{2} \cdot \sqrt{\frac{D}{C}}
$$

Equation 1 was developed using a computer analysis program developed at NRCC [1] which was validated/calibrated against tests conducted by NRCC and the Comité International pour le Développment et l'Étude de la Construction Tubulaire (CIDECT) [24]. In this equation the fire resistance, $R$, is a function of the concrete compressive strength, $f_{c}^{\prime}$, the column's effective length, $K L$, the diameter or width of the column, $D$, the applied load, $C$, and an empirical modification factor, $f$ (calibrated using the NRCC sectional analysis computer program [24]). Table 1 provides the recommended values of this factor.

Table 1. Possible values of the parameter $f$ in Eq. 1[1].

\begin{tabular}{|c|c|c|c|c|c|c|c|c|c|c|c|c|}
\hline \multirow{4}{*}{$\begin{array}{c}\text { Filling type } \\
\text { Aggregate type } \\
\text { \% of steel reinf. } \\
\text { Cover to reinf. (mm) }\end{array}$} & \multicolumn{2}{|c|}{$\begin{array}{c}\text { Plain } \\
\text { concrete }\end{array}$} & \multicolumn{8}{|c|}{ Bar reinf. concrete } & \multicolumn{2}{|c|}{$\begin{array}{l}\text { Fibre reinf. } \\
\text { concrete }\end{array}$} \\
\hline & $\mathrm{S}^{\mathrm{a}}$ & $\mathrm{C}^{\mathrm{b}}$ & \multicolumn{4}{|c|}{$\mathrm{S}^{\mathrm{a}}$} & \multicolumn{4}{|c|}{$C^{b}$} & $\mathrm{~S}^{\mathrm{a}}$ & $\mathrm{C}^{\mathrm{b}}$ \\
\hline & \multicolumn{2}{|c|}{ N/A } & \multicolumn{2}{|c|}{$<3$} & \multicolumn{2}{|c|}{$\geq 3$} & \multicolumn{2}{|c|}{$<3$} & \multicolumn{2}{|c|}{$\geq 3$} & $<1.77^{\mathrm{c}}$ & $\geq 1.77^{\mathrm{c}}$ \\
\hline & $\mathrm{N} /$ & & $<25$ & $\geq 25$ & $<25$ & $\geq 25$ & $<25$ & $\geq 25$ & $<25$ & $\geq 25$ & - & - \\
\hline$f$-Circular HSS & 0.070 & 0.080 & 0.075 & 0.080 & 0.080 & 0.085 & 0.085 & 0.090 & 0.090 & 0.095 & 0.075 & 0.085 \\
\hline$f$-Square HSS & 0.060 & 0.070 & 0.065 & 0.070 & 0.070 & 0.075 & 0.075 & 0.080 & 0.080 & 0.085 & 0.065 & 0.075 \\
\hline
\end{tabular}


A unique feature of this approach is that it explicitly accounts for the beneficial effects of including steel fibre reinforcement within the infill concrete that have been observed in (relatively few) full scale fire tests $[25,26]$. Equation 1 was developed from tests/modelling that explicitly used the E119 [10] fire, and thus it does not allow for other fire scenarios. This restricts its usefulness for performance-based design.

\section{European Approaches}

Eurocode 4 (EC4) [4] presents three alternative approaches to design a CFS column for fire. The simplest approach is to apply prescriptive requirements that are given in Table 4.7 of EC4 [4]. This gives minimum sectional properties for a given load ratio and required fire resistance.

The second of the three approaches is a simple calculation model given in Annex H of EC4 [4]. The EC4 Annex $\mathrm{H}$ approach is effectively a simplified sectional analysis calculation technique which has two distinct steps: (1) a temperature distribution over the composite cross-section is determined (using one of a number of applicable methods) after a given duration of fire exposure, and (2) from this thermal analysis a calculation of the design axial buckling capacity of the column can be made.

Several methods that could be used to calculate the temperature field within the section after a given duration of fire, ranging from detailed finite element analysis to a more simplified 1D heat transfer based on EN 1991-1-2: 2002 [14] and EN 1994-1-2: 2005 [4], in which material thermal properties can be assumed as code-specified constant values or temperature dependant values. Guidance on how to calculate the temperature profile within a section is widely available (e.g. Ref. [3]). It is noteworthy that EC4 states that in calculating the temperature distribution the thermal resistance between the steel wall and the concrete may be neglected, despite the fact that an air gap typically forms at this interface during fire [27].

Once the temperature profile within the section at a given time of fire exposure has been established, the cross-section is discretized into elements in which the temperature is assumed to be uniform, and, using a simple spreadsheet analysis, relatively simple equations can be used to check that the design resistance of the column, $N_{f, R d}$, at the given time (and temperature profile) is greater than the design load in fire, $N_{f, S d}$.

The design resistance of the column, $N_{f, R d}$, is determined from the design axial buckling load of the column during fire. This is found by assuming that all materials experience the same strain at a given time and temperature and then calculating at what strain the elastic critical or Euler buckling load, $N_{f, c}$, is equal to the plastic resistance to compression of the cross section, $N_{f i, p l, R d}[4]$ :

$$
N_{f i, R d}=N_{f i, c r}=N_{f i, p l, R d}
$$

In Eq. 3, $N_{f, c r}$ is determined as the summation of the elastic flexural rigidities of the steel tube (subscript $a$ ), the concrete (subscript $c$ ), and any internal steel reinforcement (subscript $s$ ),

$$
N_{f i, c r}=\pi^{2}\left[E_{a, \theta, \sigma} I_{a}+E_{c, \theta, \sigma} I_{c}+E_{s, \theta, \sigma} I_{s}\right] / l_{\theta}^{2}
$$

and $N_{f i p l, R d}$ is determined by summing the contributions of the respective materials. This is and taken as,

$$
N_{f i, p l, r d}=\left(A_{a} \sigma_{a, \theta} / \gamma_{M, f i, a}\right)+\left(A_{c} \sigma_{c, \theta} / \gamma_{M, f i, c}\right)+\left(A_{s} \sigma_{s, \theta} / \gamma_{M, f i, s}\right)
$$

In the above equations, $l_{\theta}$ is the buckling length in the fire situation, $E_{i, \theta, \sigma}$ is the tangent modulus of the stress-strain relationship for the material $i$ at temperature $\theta$ and for a stress $\sigma_{i, \theta}, I_{i}$ is the second moment of area the material $i$, and $A_{i}$ is the cross-sectional area of material $i$. The above parameters are calculated as the summation of the contributions from all of the respective elements in the column's cross-section at a given instant of fire exposure, assuming axial strain compatibility.

Models are given in EC4 [4] to represent the temperature induced reductions in mechanical properties of the respective materials; these can then be linearly interpolated to obtain the desired temperature dependant mechanical values at any element temperature.

Load eccentricity is accounted for in the EC4 Annex $\mathrm{H}$ [4] analysis method by replacing the design axial load in fire, $N_{f i, S d}$, with an equivalent concentric load to the column, $N_{\text {equ }}$, which is increased to reflect the 
detrimental effects of load eccentricity on fire resistance. The magnitude of the permissible eccentricity is restricted, and the following equation is used:

$N_{e q u}=N_{f i, S d} /\left(\varphi_{s} \cdot \varphi_{d}\right)$

in which $\varphi_{s}$ and $\varphi_{\delta}$ are empirically-derived parameters to account for the steel reinforcement ratio and the load eccentricity; these are given graphically in EC4 Annex H.

By calculating the temperature profile and then a resistance to load at that instant of fire exposure, a wider variety of fire scenarios can be analyzed using this approach than by using EC4's Table 4.7 [4]. This makes this method less conservative and allows greater efficiencies to be realized in structural design for fire.

The third and most advanced approach permitted by EC4 [4] is the suite of approaches termed 'Advanced Calculation' methods, in which detailed analyses (i.e. finite element models) of structures based on fundamental physical behaviour is permitted. The calculations in these models are complex, and these approaches are therefore not generally applicable to simple structural designs and are not considered in the current discussion, despite being wholly appropriate for complex or unusual design situations. Eurocode 4 [4] stipulates a number of requirements for such a detailed modelling approach. For instance, the thermal actions are to be as specified by EN 1991-1-2 [14], and the thermal properties of the materials of these steel and concrete composites should be based on those given in EC4 [4]. The advanced approaches allow for non-linearity in both thermal and mechanical properties and responses. In theory, this permits a more realistic analysis, provided that the true mechanics involved are properly understood and modelled, and that appropriate assumptions and inputs (which are sometimes not available) are used.

\section{DATABASE OF FURNACE TESTS ON CFS COLUMNS}

An exhaustive database of results from standard tests of CFS columns performed during the past 60 years has been compiled by the authors; details of the database have been presented previously [9]. While the full database contains some 370 individual test results, only 270 are from tests on unprotected CFS columns. Furthermore, the test data used for comparison against the respective design codes is somewhat different for each, since each of the approaches places different restrictions (e.g. size, infill type, concrete strength, etc.) on the cases that may be treated. Table 2 shows the restrictions applied by the respective procedures.

Table 2. Restriction application of NRCC [1] and EC Annex H [4] fire resistance design approaches.

\begin{tabular}{|c|c|c|c|c|}
\hline & \multicolumn{3}{|c|}{ NRCC [1] } & \multirow[t]{2}{*}{ EC4 Annex H [4] } \\
\hline & $P C$ & $R C$ & $F I B$ & \\
\hline Fire resistance (mins) & $\leq 120$ & $\leq 180$ & $\leq 180$ & $\leq 120$ \\
\hline \multirow[t]{2}{*}{ Axial load } & $\leq 1 \times$ & $\leq 1.7 x$ & $\leq 1.1 \times$ & \multirow[b]{2}{*}{ No restrictions } \\
\hline & \multicolumn{3}{|c|}{$\begin{array}{l}\text { Factored compressive resistance of the } \\
\text { core according to Ref. [28] }\end{array}$} & \\
\hline Eccentric loads & \multicolumn{3}{|c|}{ Not considered } & $\leq 0.5 \times(b$ or $d)$ \\
\hline Concrete strength (MPa) & $20-40$ & \multicolumn{2}{|c|}{$20-55$} & $20-40$ \\
\hline $\begin{array}{c}\text { HSS size }(\mathrm{mm}) \\
\text { Circular }(d) \\
\text { Square }(b)\end{array}$ & $140-410$ & $\begin{array}{l}165-410 \\
175-305\end{array}$ & $140-410$ & No restriction \\
\hline$\%$ of steel reinf. & N/A & $1.5-5$ & 1.75 & $0-5$ \\
\hline Concrete cover to reinf. (mm) & N/A & $20-50$ & N/A & $20-50$ \\
\hline Effective length (m) & $2-4$ & \multicolumn{2}{|c|}{$2-4.5$} & $\leq 4.5$ \\
\hline
\end{tabular}

Table 3 shows the parameters and ranges of parameters that was used to define the database of permissible tests used in the meta-analysis of the NRCC [1] approach, as permitted by the restrictions stated in Table 2. Table 4 shows similar data for the EC4 Annex H [4] design approach. Each test is reviewed and catagorized with respect to various parameters so that a critical review can be made of the applicability of the available test data for this meta-analysis and to assess which parameters are critical in the models.

The resulting NRCC [1] database includes 78 tests, with a reasonably good distribution between shape, load ratio, wall thickness, and concrete strength. The data are limited in terms of end restraint conditions, 
effective length, and concrete type. The EC4 Annex H [4] database contains 76 tests, with a good distribution section size, concrete strength, infill type, and load ratio, but a limited range of end restraint conditions, effective length, and initial load eccentricity.

Table 3. Details of specimens used in evaluation of the NRCC [1] design approach.

\begin{tabular}{|c|c|c|c|c|c|c|c|c|c|c|c|c|c|}
\hline \multicolumn{8}{|c|}{ Specimen details } & \multicolumn{6}{|c|}{ Steel tube } \\
\hline \multirow{2}{*}{\multicolumn{2}{|c|}{$\begin{array}{l}\text { Lengths } \\
\text { (m) }\end{array}$}} & \multicolumn{2}{|c|}{ Effective length $^{\mathrm{a}}$} & \multirow{2}{*}{\multicolumn{2}{|c|}{$\begin{array}{c}\text { End } \\
\text { conditions }\end{array}$}} & \multirow{2}{*}{\multicolumn{2}{|c|}{ Load ratio $^{c}$}} & \multirow{2}{*}{\multicolumn{2}{|c|}{$\begin{array}{l}\text { Section } \\
\text { shape }\end{array}$}} & \multirow{2}{*}{\multicolumn{2}{|c|}{$\begin{array}{l}\text { Section size } \\
\quad(\mathrm{mm})\end{array}$}} & \multirow{2}{*}{\multicolumn{2}{|c|}{$\begin{array}{c}\text { Wall } \\
\text { thickness } \\
(\mathrm{mm})\end{array}$}} \\
\hline & & Design & Furnace & & & & & & & & & & \\
\hline$<2.2$ & - & - & 23 & P-P & 10 & $0-0.2$ & 25 & $\mathrm{C}$ & 20 & $<200$ & 16 & $<4$ & 13 \\
\hline $2.2-3.0$ & - & 68 & 43 & P-F & 2 & $0.2-0.4$ & 31 & $\mathrm{~S}$ & 58 & $200-250$ & 27 & $4.1-5.99$ & 16 \\
\hline $3.0-3.8$ & 51 & 6 & 8 & F-F & 66 & $0.4-0.6$ & 19 & & & $250-300$ & 19 & $6-7.1$ & 31 \\
\hline$>3.8$ & 27 & 4 & 4 & & & $0.6+$ & 3 & & & $300+$ & 16 & $7.11+$ & 18 \\
\hline
\end{tabular}

Table 3. Continued.

\begin{tabular}{|c|c|c|c|c|c|c|c|}
\hline \multicolumn{8}{|c|}{ Concrete } \\
\hline \multicolumn{2}{|c|}{ Concrete type ${ }^{\mathrm{d}}$} & \multicolumn{4}{|c|}{28 day strength (MPa) } & \multicolumn{2}{|c|}{$A_{s} / A_{c}$ ratio $^{\mathrm{e}}$} \\
\hline PC & 36 & $20-25$ & 8 & $35-40$ & 20 & $<1.5 \%$ & 4 \\
\hline $\mathrm{RC}$ & 28 & $25-30$ & 9 & $40-45$ & 21 & $1.5-2.5 \%$ & 26 \\
\hline FIB & 14 & $30-35$ & 14 & $45-50$ & 6 & $2.5-3.5 \%$ & 6 \\
\hline & & & & & & $>3.5 \%$ & 6 \\
\hline
\end{tabular}

Table 4. Details of specimens used in evaluation of the EN 1994-1-2:2005 [4] Annex H design approaches.

\begin{tabular}{|c|c|c|c|c|c|c|c|c|c|c|c|c|c|c|c|}
\hline \multicolumn{10}{|c|}{ Specimen details } & \multicolumn{6}{|c|}{ Steel tube } \\
\hline \multirow{2}{*}{\multicolumn{2}{|c|}{$\begin{array}{l}\text { Lengths } \\
\text { (m) }\end{array}$}} & \multicolumn{2}{|c|}{ Effective length $^{\mathrm{a}}$} & \multirow{2}{*}{\multicolumn{2}{|c|}{$\begin{array}{c}\text { End } \\
\text { conditions }^{b}\end{array}$}} & \multirow{2}{*}{\multicolumn{2}{|c|}{$\begin{array}{l}\text { Load } \\
\text { ratio }^{c}\end{array}$}} & \multirow{2}{*}{\multicolumn{2}{|c|}{ Eccentricity }} & \multirow{2}{*}{\multicolumn{2}{|c|}{$\begin{array}{c}\text { Section } \\
\text { shape }\end{array}$}} & \multirow{2}{*}{\multicolumn{2}{|c|}{$\begin{array}{l}\text { Section size } \\
\quad(\mathrm{mm})\end{array}$}} & \multirow{2}{*}{\multicolumn{2}{|c|}{$\begin{array}{c}\text { Wall } \\
\text { thickness } \\
(\mathrm{mm})\end{array}$}} \\
\hline & & Design & Furnace & & & & & & & & & & & & \\
\hline$<2.2 \mathrm{~m}$ & 5 & 5 & 21 & P-P & 9 & $0-0.2$ & 19 & zero & 61 & $\mathrm{C}$ & 52 & $<200$ & 16 & $<4$ & 10 \\
\hline $2.2-3.0 \mathrm{~m}$ & - & 45 & 34 & P-F & 17 & $0.2-0.4$ & 32 & $<15 \%$ & 7 & $\mathrm{~S}$ & 24 & $200-250$ & 33 & $4.1-5.99$ & 21 \\
\hline $3.0-3.8 \mathrm{~m} 3$ & 38 & 14 & 9 & F-F & 50 & $0.4-0.6$ & 21 & $15-30 \%$ & 6 & & & $250-300$ & 17 & 6-7.1 & 33 \\
\hline$>3.8 \mathrm{~m} 3$ & 33 & 12 & 12 & & & $0.6+$ & 4 & $>30 \%$ & 2 & & & $300+$ & 10 & $7.11+$ & 12 \\
\hline
\end{tabular}

Table 4. Continued.

\begin{tabular}{|c|c|c|c|c|c|}
\hline \multicolumn{5}{|c|}{ Concrete } \\
\hline \multirow{2}{|c|}{ Concrete type $^{\mathrm{d}}$} & \multicolumn{2}{|c|}{28 day strength (MPa) } & \multicolumn{2}{|c|}{$A_{s} / A_{c}$ ratio $^{\mathrm{e}}$} \\
\hline PC & 45 & $20-25$ & 9 & $<1.5 \%$ & 3 \\
\hline RC & 31 & $25-30$ & 14 & $1.5-2.5 \%$ & 21 \\
\hline FIB & - & $30-35$ & 28 & $2.5-3.5 \%$ & 3 \\
\hline \multicolumn{2}{|c|}{} & $35-40$ & 25 & $>3.5 \%$ & 4 \\
\hline
\end{tabular}

${ }^{a}$ The design effective length is the code-specified effective length for the stated column end-conditions, whereas the furnace effective length is the effective length calibrated by the various testing facilities and stated in the original source references.

${ }^{\mathrm{b}} \mathrm{P}=$ pinned end condition, $\mathrm{F}=$ fixed end condition.

${ }^{\mathrm{c}}$ Ratio of applied load on the column during the test to the columns nominal strength at ambient temperature.

${ }^{\mathrm{d}} \mathrm{PC}$ - plain concrete, $\mathrm{RC}$ - steel bar reinforced concrete, FIB - steel fibre reinforced concrete

${ }^{\mathrm{e}} A_{s}$ - area of steel bar reinforcement, $A_{c}$ - area of concrete. 


\section{IMPLEMENTATION OF THE CODE-SPECIFIED APPROACHES}

\section{NRCC Equations [1]}

The NRCC [1] approach is based on a simple equation incorporating tabulated semi-empirical parameters, and as such it is relatively straightforward to implement for column of known materials and dimensions. This approach is easy and expedient to use, making it attractive to designers.

\section{Eurocode 4 Tabulated Approach [4]}

No calculations are required to use the EC4 tabulated approach. Because of the simplicity of this prescriptive approach, it is not surprising that it tends to be highly conservative in its evaluation of the likely fire resistance of a given design. Figure 1 shows a comparison of the prescribed fire resistance for all applicable column tests in the authors' test database against the test results, and shows that the tabulated resistance in EN 1994-1-2:2005 [4] is in general highly conservative. This is expected and is due to the fact that the analysis performed in developing these prescriptive requirements used twice the design buckling length when calculating the resistance to buckling at ambient, and then used this number to calibrate the load ratios. Obviously, this affects the results and ensures their safety by accounting for any possible load eccentricity or deliberately introduced moments. The approach assigns fire resistance ratings in $30 \mathrm{~min}$ intervals, making the analysis inherently conservative by up to half an hour. This approach is highly oversimplified and conservative in most cases, and it is therefore not discussed any further.

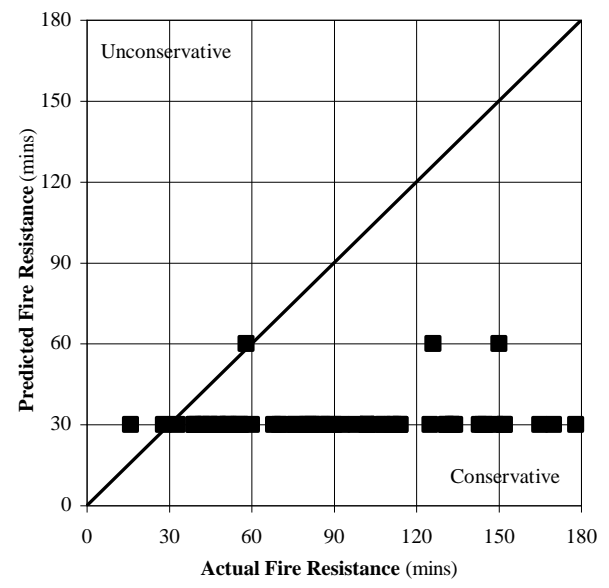

Fig. 1. Eurocode [4] tabulated fire resistance (EC4 Table 4.7) versus actual (observed) fire resistance.

\section{Eurocode 4 Annex H Approach [4]}

As described previously, the EC4 Annex H approach [4], while still considered a 'simplified' method, requires a considerable effort to determine the fire resistance time of a given CFS column. A temperature distribution over the column's cross-section needs to be determined at a given duration of exposure to fire, the capacity determined using Eqs. 2 through 6, and this capacity compared against the applicable load demand in the fire limit state. In a design situation, the prescribed (required) fire resistance of the element would normally be known and a temperature profile and load capacity would need to be determined for this duration of fire exposure only. For the purposes of the current analysis, however, the goal was to predict the fire resistance of a given column, and the temperature distribution and column capacity are needed for essentially every instant during the entire duration of fire.

While a number of techniques exist to determine the temperature distribution in a circular or square CFS column during fire, finite element heat transfer analysis was used in the current study to determine the temperature distribution for each and every individual section type and size in the test database at oneminute intervals. The input parameters to the analysis, apart from the cross-sectional dimensions, were the thermal properties of steel and concrete, and the thermal insult (fire exposure). The thermal insults used in the majority of the tests were ISO 834 [11] standard fires (or similar).

For simplicity it was assumed in the current analysis that the surface temperature of the unprotected CFS column would the same as that of the fire. This simplifying assumption is reasonably common in the 
analysis of unprotected steel elements and is reasonably consistent with steel temperatures measured in tests [24]. It should be noted in the context of the current discussion that this assumption is conservative, since in reality the temperature of the fire will be slightly higher than the steel surface temperature. This will result in EC4 Annex $\mathrm{H}$ fire resistance predictions that are slightly conservative as compared with a more rigorous surface heat flux analysis; this conservatism is not considered critical for the current paper.

EN 1994-1-2: 2005 [4] provides thermal properties for both structural and reinforcing steel, as well as for concrete. Two approaches are permitted for each material: one in which thermal properties are temperature dependant, and one in which constant values are assumed. In the current analysis, the simplifying case of constant values for thermal conductivity, $\lambda$, and heat capacity, $c$, was used. The specific heat capacity for steel and concrete were therefore taken as $c_{a}=600 \mathrm{~J} / \mathrm{kg} \cdot \mathrm{K}$ and $c_{c}=1000 \mathrm{~J} / \mathrm{kg} \cdot \mathrm{K}$ for steel and concrete, respectively, and the thermal conductivities were taken as $\lambda_{a}=45 \mathrm{~W} / \mathrm{m} \cdot \mathrm{K}$ and $\lambda_{c}=1.6 \mathrm{~W} / \mathrm{m} \cdot \mathrm{K}$, as recommended for simple calculation models in EC4 Annex H [4]. This approach will also slightly increase the conservatism of fire resistance prediction.

Once the temperature distributions were obtained, the load capacity of the section was determined. Guidance on how to calculate the load capacity according to the EC4 Annex H approach is available in a number of publications (e.g. Refs. [3,7]). Typically, the steel tube is assumed to have uniform temperature and the concrete cross-section is divided into ringed segments of equal thickness. This is shown schematically in Fig. 2, where six concrete layers have been chosen. Clearly, the more layers that are taken the more refined the prediction, however between five [7] and ten [3] layers have been suggested in the literature; in the current analysis seven layers were assumed.

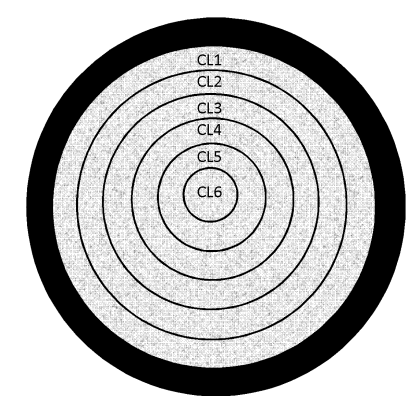

(a)

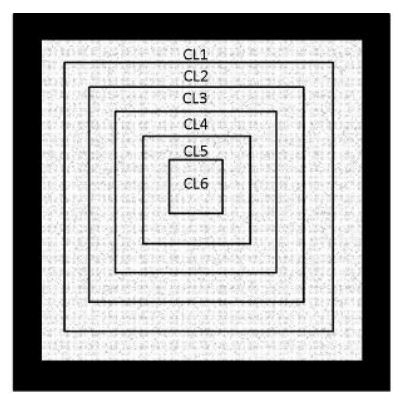

(b)

Fig. 2. (a) Circular and (b) square segmentation used in EC4 Annex H [4] analysis (CLi = concrete layer $i$ ).

Each of the concrete rings is assumed to have a uniform temperature at any given instant time, with temperatures based on the heat transfer analysis described previously. The determination of the temperature for the concrete layers in circular sections is straightforward due to axisymmetry. The situation in a square section is more complicated; in a square section the temperature at the corners is higher than at the middle of the flat faces. However precedence exists [7] to assume an equivalent uniform temperature in each concrete layer in the square section, provided that the uniform temperature chosen for the layer leads to the same (or smaller) contribution to either the plastic resistance in compression or the cross-section's flexural stiffness as would a more complete summation of a 2-D grid of concrete elements. A heat transfer analysis was therefore performed (using ABAQUS) for the square sections assuming a 2-D square element mesh and the average temperature in each element was determined. The average of all of the element temperatures within a given square ring was then determined and taken as the equivalent constant temperature for that concrete layer. An analysis of the mechanical response of the layer using the averaged temperature versus the response using a rigorous summation of the mechanical properties of each square element in the layer showed that the averaged temperature for the layer provides an accurate estimate for the load capacity analysis. This means that a full two dimensional discretization is not required.

After the temperature of each layer was determined, its mechanical properties were found by interpolation of Tables 3.1 through to 3.4 of EN 1994-1-2:2005 [4] and these were applied within Eq. 4 through Eq. 6.

\section{MEANS OF STATISITICAL COMPARISON}

The NRCC [1] and EC4 Annex H [4] methods of analysis are the two currently available methods of analysis that are, due to their relative simplicity, most likely to be applied by structural (or structural fire) 
engineers in performing fire resistance design of CFS columns. The remainder of this paper presents a statistical comparison (meta-analysis) of these two approaches by comparing their predictions against their respective applicable fire test result databases. The comparison is made on the basis of simple statistical measures of conservatism, accuracy, and precision. The statistical measures are also used below to investigate the possible influences of various potentially important parameters on the fire resistance of unprotected CFS columns.

The mean error, ME, is used to give an indication of a model's conservatism (and, to a certain extent, its accuracy of prediction) and was calculated by taking the average percent error between the model prediction and the experimentally observed value for each result in the database for each respective design approach. The mean absolute error, MABE, gives an indication of a model's accuracy, and was calculated by taking the average absolute percent error of prediction. Finally, the standard deviation of the error of prediction, $\sigma$, provides an indication of a model's precision. The analysis assumes that the errors of prediction are normally distributed about their mean; the standard deviation can therefore be used to judge the statistical confidence in a model's predictive ability.

\section{QUANTITATIVE COMPARISON OF APPROACHES}

Figure 3a shows the fire resistance predictions of the NRCC [1] design approach versus the observed fire resistance times for each applicable column in the database. Figure $3 b$ shows the same comparison for the EC4 Annex H [4] design approach. Both figures show diagonal lines representing a one-to-one $(1: 1)$ prediction (i.e. zero error). Points that fall above the 1:1 line represent under-predictions (unconservative), whereas points below the line are conservative. The dashed line in these figures represents the mean error of prediction (i.e., a straight line through the origin that seeks to minimize the total error of prediction).

The ME of prediction for the NRCC design approach is $17 \%$, which means that on average this approach over-predicts the fire resistance by $17 \%$; the approach is unconservative on average. Furthermore, the MABE of the NRCC [1] approach is $40 \%$, meaning that the average magnitude of the error of prediction is $40 \%$. The standard deviation of the error of prediction is $59 \%$, meaning that the approach's mean error of prediction is 0.29 standard deviations above the 1:1 line (i.e. on the unconservative side). The statistical confidence in the model is relatively low and, assuming that the error of prediction is normally distributed, only about $40 \%$ of the model predictions can be expected to be on the conservative side of the 1:1 line.

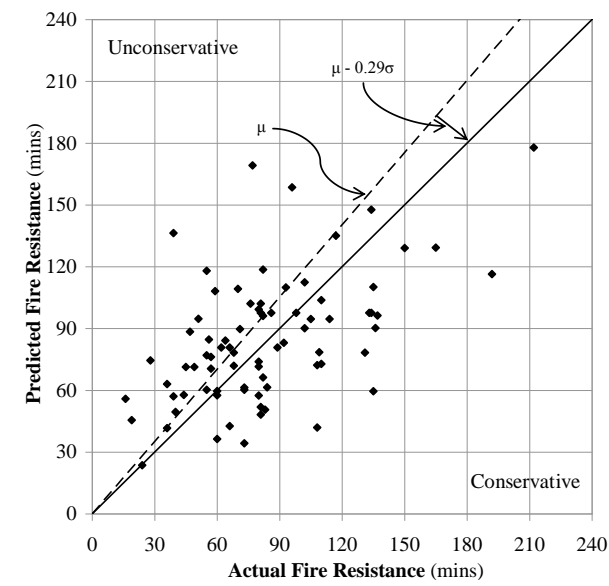

(a)

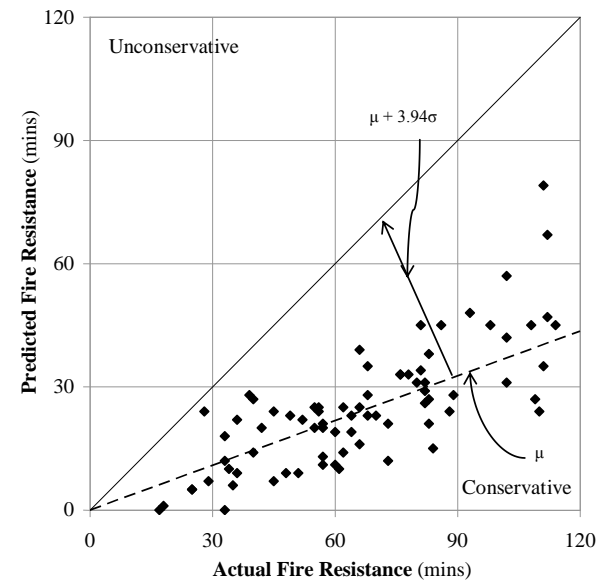

(b)

Fig. 3. Predicted fire resistance versus observed fire resistance based on (a) NRCC [1] design approach; (b) EC4 Annex H [4] design approach.

Figure $3 \mathrm{~b}$ shows that the predictions of the EC4 Annex H [4] approach are similarly imprecise, with a MABE of $64 \%$. This approach is less accurate than the NRCC [1] approach, with a ME of $-64 \%$, however since the $M E$ value is negative this approach is conservative (on average). The standard deviation of the error of prediction is $16 \%$ in this case, such that the mean error of prediction is 3.94 standard deviations below the 1:1 line. Therefore, almost all predictions are expected to be conservative by, on average, $64 \%$. 
Figure 3 shows that considerable imprecision and variance exist in both the NRCC [1] and EC4 Annex H [4] design approaches; this leads to a lack of statistical confidence in both approaches. The lack of accuracy could be because the data provided by the testing reports omit key pieces of information (true effective length, for instance) or to the model not properly capturing the true mechanics of CFS columns in fire or missing other key aspects behaviour observed in tests (alternative failure modes, local buckling, etc.).

EC4 Annex H [4] allows consideration of eccentric loads applied to the specimen, and modification factors are then applied to the loads to create an effective concentric design load to be assessed. The difference in eccentric to concentric loading is considerable. ME for concentric and eccentric loading is $-60 \%$ and $-77 \%$ respectively, MABE is $60 \%$ and $77 \%$ respectively and standard deviations are 0.15 and 0.13 respectively. The larger conservatism for eccentrically loaded columns should be investigated and addressed.

\section{Parameters Affecting Performance of the Design Approaches}

In an attempt to better understand where the variability in the predictions arises, a more detailed statistical analysis was performed wherein the database was partitioned based on a number of different parameters, and the ability of the two design approaches to deal with these more specific data sets was explored.

\section{Effect of Column Cross-Sectional Size}

Figure 4a shows the effect of column diameter on the conservatism, accuracy, and precision of fire resistance prediction for the NRCC [1] approach. This figure shows that the NRCC [1] approach is, in general, less conservative for columns of larger diameters, in that it considerably over estimates fire resistance (on average). This is an important observation because columns in real buildings tend to fall at the larger end of the spectrum of possible column sizes. This result suggests that additional research on columns of large diameter is warranted if the NRCC [1] procedure is to be applied in practice. The statistical confidence in prediction for columns with diameters greater than $300 \mathrm{~mm}$ is dramatically reduced (although this is partly because relatively few test results are available). The mean error of prediction for the columns with a diameter above $300 \mathrm{~mm}$ lies 0.94 standard deviations above the $1: 1$ line; i.e. only $19 \%$ of the predictions for section sizes greater than $300 \mathrm{~mm}$ are likely to be conservative on the basis of the available data. Figure 4b shows that the effect of section size on the EC4 Annex H [4] design approach is not obvious, and for this approach, there appear not to be any clear differences in performance based on section size.

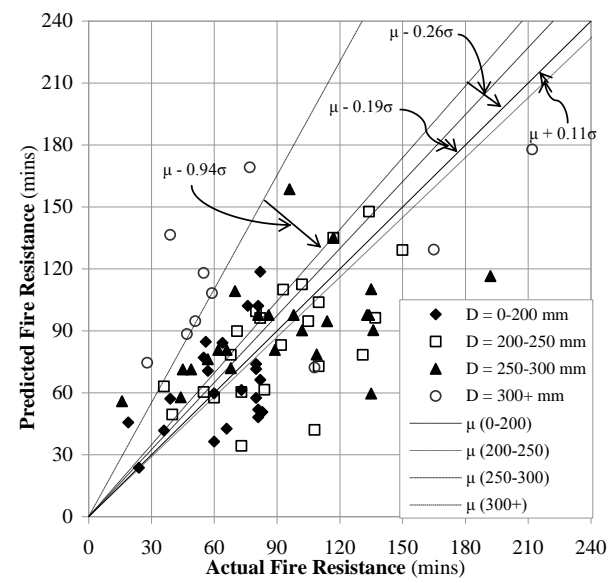

(a)

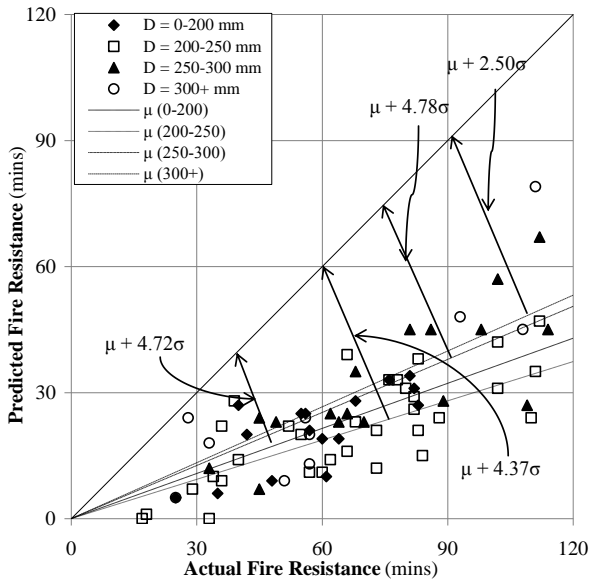

(b)

Fig. 4. Predicted fire resistance versus observed fire resistance for columns of different effective diameters based on: (a) the NRCC [1] design approach; (b) the EC4 Annex H [4] approach.

\section{Effects of Effective Length and Fire Test Load Ratio}

A key parameter in the calculation of predicted fire resistance times using both design approaches is the effective (buckling) length of the column. In a real building, the effective length for design would be defined by the respective codes on the basis of the rotational restraint conditions acting at a column's extremities. This poses a problem for the comparative analyses presented herein, since some of the 
available test reports quote only idealised end conditions (i.e. pinned-pinned, pinned-fixed, fixed-fixed) (e.g. Ref. [24]), whereas others give both the idealized column end conditions and 'calibrated' effective lengths based on the specific testing furnace used and the judgement of the researchers (e.g. Ref. [29]). Furthermore, the available design codes give column effective lengths which are to be used for fire resistant design of columns in non-sway frames [4,28], and in many cases these do not match up with the effective length values quoted by researchers for furnace tests using these same end conditions. To reconcile this, the effective lengths quoted in test reports have been used when applying the respective design approaches, rather than using the design values that would be imposed by the codes $[4,28]$ for these same columns. This is appropriate since it allows a better comparison of whether the respective approaches capture the true mechanics of CFS columns' response to fire, or whether they are essentially pure empiricism.

Figure 5a shows a comparison of the NRCC [1] and EC4 Annex H [4] design approaches in terms of ME, $\mathrm{MABE}$, and standard deviation (Std Dev) of the error of prediction when using either the quoted furnace effective length or the design effective length as given in the respective code. In this figure the databases have also been partitioned on the basis of the fire test load ratio. It is noteworthy that the comparisons for load ratios greater than 0.6 should be treated with caution, since the number of tests is too few to be considered statistically rigorous.

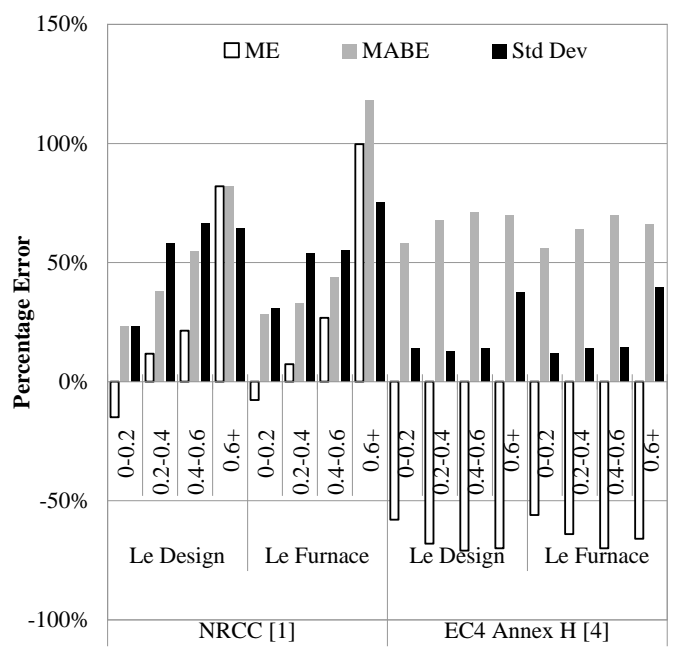

(a)

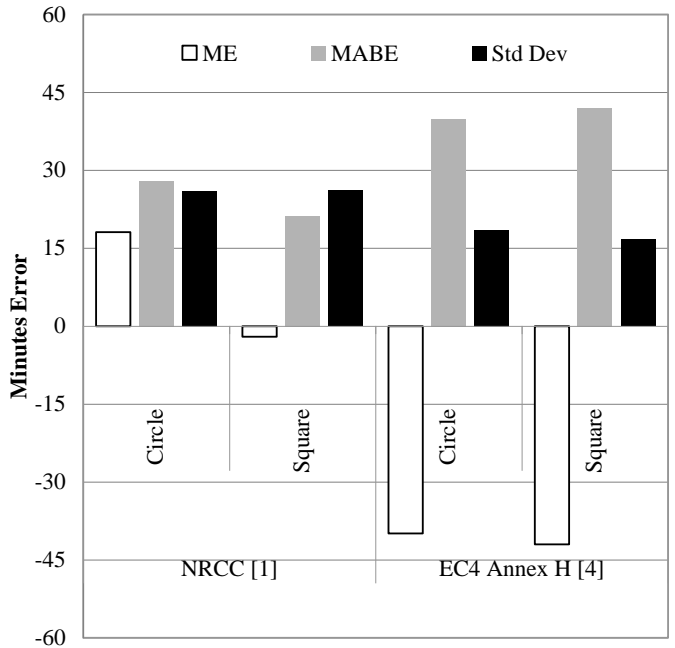

(b)

Fig. 5. Comparison of ME, MABE, and Std Dev for NRCC [1] and EC4 Annex H [4] approaches, considering: (a) both quoted furnace (Le Furnace) and design (Le Design) effective length separated based on load ratio; (b) data separated based on cross-sectional shape.

It is apparent in Fig. 5a that the NRCC [1] approach is most conservative and most accurate for columns with low applied loads during fire, and it becomes less accurate, less precise, and less conservative as the load ratio increases. While the reasons for this are unclear, this again suggests that this approach fails to capture the mechanics of CFS column response and/or failure during fire. This is also an important finding since load ratios in design are typically in the range of 0.4 to 0.6 . Using the quoted furnace effective length rather than the design effective length (excluding the $0.6+$ load ratios) has only a minor effect on model performance, but slightly improves the predictions for load ratios within the range between 0.2 and 0.6 .

With regard to the EC4 Annex H [4] approach, Fig. 5a shows that as the load ratio increases the precision, accuracy and conservatism of this approach remain reasonably constant. The EC4 Annex H approach is much more conservative than the NRCC approach, particularly for columns with practical load ratios.

For the EC4 Annex H [4] approach, using the quoted furnace effective length rather than the design effective length has no obvious impacts on the quality of fire resistance prediction due to the fire resistance of the column being determined when the buckling resistance and the resistance to crushing are equal. A change in effective length will not affect the resistance to crushing, but will have an impact on the buckling resistance. As Fig. 5a shows, the change in the effective length between the design and furnace effective lengths creates little change on the model's accuracy, suggesting that the columns tested are generally 
relatively stocky. The stiffness in fire for a CFS column is considerably higher than that of an unfilled tube of the same effective length so that fire resistance in these cases tends toward being governed by crushing rather than buckling failures.

\section{Effect of Cross-Sectional Shape (Circular or Square)}

Figure $5 \mathrm{~b}$ shows the effect of the shape of the column on the performance of the respective design approaches. The NRCC [1] approach over-predicts the fire resistance of the circular columns (on average), whilst it slightly under-predicts the fire resistance for square columns. The NRCC approach accounts for column shape using a semi-empirical modification factor, $f$ (given in Table 1). On the basis of the analysis presented herein, this factor appears to not properly account for column shape, since one would expect similarly conservative predictions for circles and squares if this were the case. Again, it appears that the NRCC [1] approach fails to capture important aspects of CFS columns' response in fire.

Figure 5b shows that the EC4 Annex H [4] approach takes shape equally well into account shape for both shapes with squares being slightly more conservative than circles, and these are more conservative than the NRCC [1] approach for both shapes. The Annex H approach takes shape into account by considering the area of concrete in each segment. It is unclear why both models should be more conservative for square columns, although again this suggests that there is something fundamentally different about the way that square sections react to fire as compared with the circular columns. Possible reasons for this could be the effects of confinement of the core concrete in circular columns which would not be present to the same extent in square columns, or the non-uniform thermal profile over a rectangular cross-section (with hotter corners) as compared with the axisymmetric thermal distribution in circular columns. Additional research is required to better understand these issues.

\section{Effect of Testing Laboratory}

An issue of particular interest is whether the respective models are better predictors for columns tested in one testing laboratory versus another. Standard fire test furnaces globally are known to be different from one another in a host of potentially important respects (mostly with respect to the heat flux applied to the tested element, resulting from different fuel sources, furnace linings, technique for measurement of gas phase temperature, control of the furnace, etc, but also in terms of the ratio of heated length to total length, loading configuration, rotational fixity, etc). It is interesting to ask whether the NRCC [1] model, for instance, is a better predictor of test results obtained in the NRCC column furnace.

Figure 6a shows a comparison of the ME, MABE, and Std Dev for both the NRCC [1] and EC4 Annex H [4] design approaches, with the database partitioned based on the laboratory in which the respective tests were performed. Six different testing locations are represented in the data: NRCC (Canada), CSTB (France) CTICM (France), Brunswick (Germany), Monash University (Australia), and Takenaka Technical Research Laboratory and General Building Research Corporation (Japan). The testing locations used in the comparison are different between the two design approaches because of the varying restrictions of applicability of certain tests in the respective codes.

Figure 6a shows that there are considerable differences in the predictive capabilities of the approaches when comparison is made between testing labs. This variation between the test centres may be due to the dates when the tests were carried out, with NRCC tests generally being more recent and therefore using more advanced equipment and techniques for measurement (in the 1980s and 1990s) than were available when the Brunswick, CTICM, and CSTB tests were performed (mostly during the early 1970s). Smaller data sets, such as for the most recent testing at Monsah University (2000s) have high variance due to small numbers of samples, and should therefore be treated with caution.

\section{Effect of Steel Tube Wall Thickness}

Figure 6b shows a comparison of ME, MABE, and Std Dev for both the NRCC [1] and EC4 Annex H [4] design approaches, in this case with the data partitioned based on steel wall thickness. The NRCC [1] approach does not explicitly use steel wall thickness as a variable in determining the fire resistance of a CFS column, and its fire resistance predictions become less accurate, less conservative, less precise, and more variable as the wall thickness increases.

The standard deviation for the EC4 Annex H [4] approach remains reasonably constant for the changing wall thickness, suggesting that whilst not perfectly accounting for the wall thickness this approach is at 
least reasonably consistent. The predictions for thinner wall sections in the EC4 Annex H [4] approach are slightly more conservative. This could be due to the rapid heating of thin unprotected steel tubes and their rapid thermal expansion, which could cause the early formation of an air gap between the steel tube and concrete infill. This in turn would speed the temperature rise in the steel tube but slow the heat transfer into the concrete, allowing it to support the imposed load for longer than might be assumed by the Annex $\mathrm{H}$ procedures. The EC 4 Annex H [4] approach may also underplay the ability of the concrete core to carry loads during fire, since this approach is slightly more conservative for columns with smaller wall thicknesses that rely largely on the load carrying capability of the core.

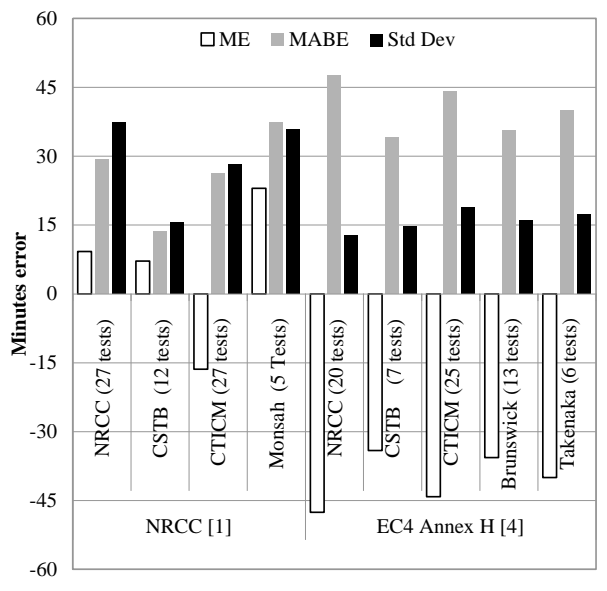

(a)

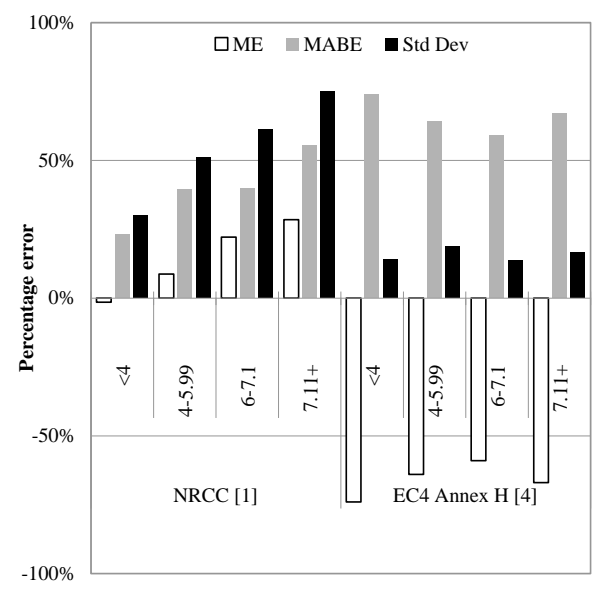

(b)

Fig. 6. Comparison of ME, MABE, and Std Dev for both the NRCC [1] and EC4 Annex H [4] design approaches with data separated based on: (a) testing laboratory; (b) steel wall thickness.

The above observations again suggest that both approaches fail to capture the relevant mechanics of these columns during fire. The trends would appear to indicate that the behaviour of the steel tube is more important than assumed by either of the approaches, since their conservatism generally reduces when the steel tube plays a larger structural role. This could be due to the impacts of gap formation (as previously noted) and/or slip between the concrete and the steel tube, or to local buckling of the steel tube wall, all of which are commonly observed during testing of CFS columns in fire [9]; none of which are accounted for in either of the design approaches discussed herein.

\section{CONCLUSIONS AND RECOMMENDATIONS}

A brief review of some of the available fire resistance design approaches for CFS columns in North America [1] and Europe [4] has been presented. The primary goal has been to statistically evaluate the performance of the respective approaches by comparing code predicted fire resistance times against observed fire resistance times from available standard furnace tests carried out worldwide.

The focus of the comparisons presented has been on the NRCC [1] and EC4 Annex H [4] fire resistance design approaches, since these are currently the most likely approaches to be used in practice. The simple tabulated prescribed fire resistance calculation procedure given in Table 4.7 of EN 1994-1-2:2005 [4] is generally highly conservative and has not been considered in detail.

Both the NRCC [1] and EC4 Annex H [4] design approaches are highly variable and provide only minimal statistical confidence in their ability to realistically predict the fire resistance of CFS columns. The EC4 Annex $\mathrm{H}$ approach is far more conservative than the NRCC approach, but displays similar variability, with a MABE of close to $40 \%$ for the NRCC [1] approach and $65 \%$ for EC4 Annex H [4].

The NRCC [1] approach, while easy and rapid to use, is in general less accurate, less conservative, less precise, and more variable than the EC4 Annex H [4] simple calculation model. This is probably because the NRCC model is essentially a semi-empirical best fit model which is based both on test results and on a relatively simple numerical model (which was developed and calibrated on the basis of those same test results). As such, fire resistance is determined not by using explicit physical characteristics but rather by 
applying a calibrated $f$ factor, as described in Table 1 and calibrated based on a relatively small number of tests. As shown when evaluated against a larger database, the NRCC model performs relatively poorly. This approach is also limited as it calibrated against the ASTM-E119 [10] standard fire curve and it therefore cannot allow for the use of any other design fire; it is not easily applicable for performance-based design of CFS columns for fire. The NRCC approach is a particularly poor predictor for large, heavily loaded, circular columns and thick-walled tubes. It would therefore appear that the NRCC design approach fails to account for the true mechanics at play during the fire exposure of CFS columns to fire, and that additional research is needed to refine the model.

The EC 4 Annex H [4] approach to predict the fire resistance of CFS columns, while also highly variable, appears to be slightly more robust than the NRCC approach. This is not surprising, since the Annex H approach is clearly rooted in physical realities rather than based on empirical curve fits. This approach is very conservative and shows relatively consistent variability amongst various column parameters investigated herein. The effects of load ratio and wall thickness both need to be better addressed, since neither of these characteristics' influence on the fire resistance time appear to be accurately accounted for. This could be due to gap formation and subsequent effects on heat transfer, slip, and local buckling of the steel tube leading to failure. Importantly, the EC4 Annex H model allows for the use of non-standard (design) fire scenarios and is therefore applicable in performance-based design.

In conclusion, both design approaches treated herein do not appear to properly account for the true mechanics at play during the fire exposure of a loaded CFS column. In addition, because they are based on test results from standard testing furnaces, both approaches are limited in terms of their applicability to columns of realistic size, slenderness, concrete strength, concrete infill type, etc. Additional testing is needed to develop a defensible understanding of the fundamental mechanics involved so that better design approaches can be proposed which properly account for all of the relevant parameters.

\section{ACKNOWLEDMENTS}

We gratefully acknowledge the support of Arup Fire, The Ove Arup Foundation, The Royal Academy of Engineering, and the Engineering and Physical Sciences Research Council. The authors gratefully acknowledge the support of the School of Engineering at the University of Edinburgh, which is part of the Edinburgh Research Partnership in Engineering and Mathematics.

\section{REFERENCES}

[1] Kodur, V., (2007) Guidelines for Fire Resistance Design of Concrete-Filled Steel HSS Columns State-of-the-Art and Research Needs, Steel Structures 7: 173-182.

[2] Communities \& Local Government, Approved Document B - Vol. 2 - Buildings other than Dwelling Houses, RIBA Enterprises, London, UK, 2007.

[3] Lennon, T., Moore, D.B., Wang, Y.C. \& Bailey, C.G., Designer's Guide to EN 1991-1-2, 1992-12, 1993-1-2 \& 1994-1-2, Thomas Telford, London, UK, 2007.

[4] CEN, BS EN 1994-1-2, Eurocode 4: Design of composite steel and concrete structures, General rules, Structural fire design, BSI Publications, UK, 2005.

[5] CEN, NA to BS EN 1994-1-2, UK National Annex to Eurocode 4, BSI Publications, UK, 2008.

[6] Wang, Y.C. and Orton, A.H., (2008) Fire Resistant Design of Concrete Filled Tubular Steel Columns, The Structural Engineer, October, pp. 40-45.

[7] Aribert, J.M., Renaud, Ch. and Zhao, B., (2008) Simplified fire design for composite hollowsection columns, Structures and Buildings, 161(6): 325-336. http://dx.doi.org/10.1680/stbu.2008.161.6.325

[8] Park, S., Song, K., Chung, K. and Choi, S., "Characteristics Analysis of the Performance Design Equations for the Fire Resistance of Concrete-Filled Steel Tube Columns", SiF'08, June 2008, pp. 584-593.

[9] Rush, D., Bisby, L., Jowsey, A., and Lane, B., "Structural Fire Performance of CFS Sections: State-of-the-Art \& Knowledge Gaps", Interflam, July 2010, pp. 57-70. 
[10] ASTM, ASTM E119: Standard Test Methods for Fire Tests of Building Construction and Materials, West Conshohocken, USA, 2007.

[11] ISO, ISO 834: Fire resistance tests-elements of building construction. International Standards Organization, Geneva, Switzerland, 1975.

[12] Stern-Gottfried, J., Law, A., Rein, G., Gillie, M., and Torero, J.L., "A Performance Based Methodology Using Travelling Fires for Structural Analysis", $8^{\text {th }}$ International Conference on Performance-Based Codes \& Fire Safety Design Methods, June 2010, pp. 373-384.

[13] Law, A., Stern-Gottfried, J., Gillie, M., and Rein, G., "The Influence of Travelling Fires on the Response of a Concrete Frame", SiF'10, June 2010, pp. 189-196.

[14] CEN, BS EN 1991-1-2: Eurocode 1, Actions on structure - Part 1-2: General actions - actions on structures exposed to fire, BSI Publications, UK, 2002.

[15] Wang, Y.C., and Orton A.H., (2008) Fire Resistant Design of Concrete Filled Tubular Steel Columns, The Structural Engineer, October, pp. 40-45.

[16] Wang, Y.C., (2005) Performance of steel-concrete composite structures in fire, Progress in Structural Engineering and Materials, 7: 86-102. http://dx.doi.org/10.1002/pse.197

[17] GJB 4142-2000, Part 1: Design Code for Concrete Filled Steel Tubes with Square Sections, Chinese PLA Press (in Chinese), Beijing, PR China, 2000.

[18] GB 50045-95, Code for Fire Protection Design of Tall Buildings, National Standard of The People's Republic of China (in Chinese), Beijing, PR China, 2005.

[19] DL/T, Chinese design code for steel-concrete composite structures, DL/T 5085-1999, Chinese Electricity Press (in Chinese), Beijing, PR China, 1999.

[20] NBCC, National Building Code of Canada, National Research Council of Canada, Ottawa, Canada, 2005.

[21] ASCE, ASCE/SFPE 29: Standard Calculation Method for Structural Fire Protection, American Society of Civil Engineers, Reston, USA, 1999.

[22] ACI, ACI 216.1M-07: Standard Method for Determining Fire Resistance of Concrete and Masonry Construction Assemblies, American Concrete Institute, Detroit, USA, 2007.

[23] Ruddy, J.L., Marlo, J.P., Ioannides, S.A. and Alfawakiri, F., "Fire Resistance of Structural Steel Framing," Steel Design Guide 19, American Institute of Steel Construction, Chicago, USA, 2003.

[24] Kodur, V.K.R, (1999) Performance-based fire resistance design of concrete filled steel columns, Journal of Constructional Steel Research, 51: 21-36. http://dx.doi.org/10.1016/S0143974X(99)00003-6

[25] Kodur, V.K.R, and Lie, T.T., "Experimental studies on the fire resistance of circular hollow steel columns filled with steel fibre reinforced concrete," NRC Internal Report No. 691, National Research Council of Canada, Ottawa, Canada, 1995.

[26] Kodur, V.K.R, and Lie, T.T., "Experimental studies on the fire resistance of square hollow steel columns filled with steel fibre reinforced concrete, " NRC Internal Report No. 662, National Research Council of Canada, Ottawa, Canada, 1996.

[27] Ding, J., and Wang, Y., (2008) Realistic modelling of thermal and structural behaviour of concrete filled tubular columns in fire, Journal of Constructional Steel Research 64: 1086-1102. http://dx.doi.org/10.1016/j.jcsr.2007.09.014

[28] CSA, CAN/CSA-S16.1-M94: Limit states design of steel structures, Canadian Standards Association, Toronto, Canada, 1994.

[29] Stanke, J., "Uuber die Auswetung von Ergebnissen ausgefurhrter Brandversuche mit Schlussfolgerungen und Vorschlag fur ein Versuchproramm”, Report 15C1, Comité International pour le Développement l'Etude de la Construction Tubulaire, France, 1975. 